dicina Dentária da Universidade de Lisboa com o objetivo de reparar o dente 21 que havia sofrido fartura do bordo incisal e ângulo distal há vários anos. Paciente do género masculino, 39 anos, seguido na clínica universitária, após colocação de implante no dente 21 apresentava necessidade de aumento mesmo-distal da coroa do dente 11 de modo a obter um sorriso harmonioso. Em ambos os casos, após enceramento diagnóstico em laboratório, foi feita uma matriz de silicone palatina e reconstrução através da técnica de estratificação com resina composta. Discussão e conclusões: A realização de enceramento diagnóstico permite, não só a criação de uma chave de silicone, mas também a visualização do resultado final pretendido, podendo ser complementado, ou não, com um mock-up. A utilização de matriz de silicone palatina auxilia na colocação na primeira camada de resina composta, permitindo uma redução do tempo de trabalho e também uma reconstrução mais precisa do ponto de vista anatómico e de oclusão. Concluindo, o enceramento diagnóstico e a utilização de matriz de silicone são essenciais para o trabalho do médico dentista e sucesso do resultado final das restaurações estéticas anteriores.

http://doi.org/10.24873/j.rpemd.2019.12.504

\#041 Pulpotomia parcial numa fratura complicada de incisivos permanentes - controlo 5 anos

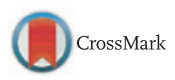

Isabel Magalhães Gomes*

FMDUL

Introdução: Estima-se que $25 \%$ crianças em idade escolar sofrem algum tipo de traumatismo dentário, alguns com envolvimento pulpar. Num dente definitivo imaturo todos os esforços devem ser feitos para preservar a vitalidade pulpar de forma a permitir a continuação do desenvolvimento radicular. Descrição do caso clínico: Paciente com 8 anos de idade observado 3 dias após uma fratura de esmalte - dentina - polpa dos dois incisivos centrais superiores. O paciente negou existência de dor espontânea. No exame objectivo intra-oral foram diagnosticadas exposições pulpares em ambos os incisivos (no 21 com protrusão da polpa), percussão ligeiramente dolorosa, sem queixas à palpação, ausência de bolsas periodontais superiores a $3 \mathrm{~mm}$, mobilidade classe I e resposta positiva ao teste ao frio em ambos os incisivos. No exame radiográfico não se identificaram fracturas radiculares nem radiolucências periradiculares. Após anestesia foi realizada a pulpotomia parcial com broca diamantada. A hemorragia foi controlada com água e subsequentemente aplicou-se o Mineral Trióxido Agregado (MTA). Após 10 minutos aplicou-se por cima do MTA um ionómero de vidro e o paciente foi dispensado. Decorridas 2 semanas o paciente encontrava-se assintomático e com resposta positiva ao teste ao frio. Realizou-se a remoção parcial do ionómero de vidro e foi realizada a restauração direta a compósito. Nas consultas de controlo aos 6 meses, 1 ano, 2 anos e 5 anos o doente permaneceu assintomático e sem evidência de lesões radiolúcidas nos exames radiográficos. Discussão e conclusões: As orientações terapêuticas da associação dentária de traumatologia internacional privilegiam a terapia pulpar vital nesta situação clinica. Segun- do Cvek 1978 e Cvek e col. 1982 nem o intervalo de tempo decorrido após o trauma, nem o tamanho da exposição dentária afectam o prognostico deste tratamento. Exposições pulpares traumáticas de dentes permanentes podem ser tratadas com sucesso através do método descrito, mesmo em casos como o descrito em que há protrusão da polpa. O método descrito tem a vantagem de manter o feixe vasculo-nervoso permitindo a normal formação radicular.

http://doi.org/10.24873/j.rpemd.2019.12.505

\section{\#042 Reabilitação funcional e estética combinando prótese removível e resinas compostas}

Fabio Santos*, Melanie Billerach, Ligia Pereira da Silva, Sandra Gavinha, Patricia Manarte Monteiro

Universidade Fernando Pessoa

Descrição do caso clínico: Paciente do género feminino, 64 anos, compareceu na Clínica Pedagógica de Medicina Dentária da FCS-UFP, com queixa de edentulismo nos sectores posteriores e descontente com a estética do seu sorriso. Realizaram-se radiografias interproximais e ortopantomografia como meios complementares de diagnóstico. Diagnosticou-se a presença de extrusões dentarias, devido aos espaços edêntulos antagonistas, assim como uma ligeira perda de DVO, tendo sido observados diastemas no setor ântero-superior. Foram propostas várias abordagens terapêuticas, mas devido às limitações económicas da paciente, optou-se pela reabilitação com próteses removíveis esqueléticas superior e inferior, com aumento de DVO de $2 \mathrm{~mm}$, e restaurações diretas para fechamento dos diastemas do $2^{\circ}$ sextante. Efetuou-se um enceramento diagnóstico, através do qual se confecionou uma chave de silicone para o mock-up e uma chave de silicone palatina. Numa primeira fase, realizou-se um mock-up direto em resina bis-acril Structur 2 (cor A3) para verificar a forma final das restaurações, recorrendo ao fechamento completo do diastema $11 / 21$. Como a paciente não gostou do resultado, foi então feito um novo enceramento para fechamento parcial do diastema. As restaurações foram efetuadas com a estratégia adesiva etch-and-rinse, utilizando o sistema adesivo Optibond Solo Plus (Kerr) e aplicando compósito Synergy D6 (Coltene), recorrendo a Esmalte Universal e Dentina A2/B2 através da técnica de estratificação de compósitos. Discussão e conclusões: Existem várias opções de tratamento para reabilitação oral e harmonização do sorriso. No entanto, a realização de próteses removíveis esqueléticas tem a vantagem de ser económica para o paciente, enquanto que a utilização de resina composta, de forma direta, no encerramento dos diastemas é uma técnica que tem como vantagens ser económica e conservadora, dado que não foi necessária qualquer preparação dentaria. A reabilitação oral global deve ser adaptada tanto à situação económica do paciente como às suas expectativas, sendo que estas devem ser realistas. Sendo assim, as próteses removíveis continuam a ser uma boa opção terapêutica e o encerramento de diastemas, utilizando restaurações diretas, constitui uma opção viável para equilibrar a harmonia do sorriso, respondendo às expectativas estéticas do paciente.

http://doi.org/10.24873/j.rpemd.2019.12.506 